\title{
FACTORIZATION OF LIPSCHITZ OPERATORS ON BANACH FUNCTION SPACES
}

\author{
D. Achour, E. Dahia, P. Rueda, E. A. Sánchez Pérez and R. Yahi
}

Abstract. Let $(X, d)$ be a pointed metric space. Let $T: X \rightarrow Y_{1}(\mu)$ and $S: X \rightarrow Y_{2}(\mu)$ be two Lipschitz operators into two Banach function spaces $Y_{1}$ and $Y_{2}$ over the same finite measure $\mu$. We show which are the vector norm inequalities that characterize those $T$ and $S$ for which $T=M_{g} \circ S$, for some multiplication operator $M_{g}: Y_{2} \rightarrow Y_{1}$. Our ideas give rise to MaureyRosenthal type factorization results for Lipschitz operators. We provide some applications on the Lipschitz structure of metric subsets of Banach function spaces.

Mathematics subject classification (2010): Primary 46E30, 47B38, Secondary 46B42.

Keywords and phrases: Banach function spaces, Lipschitz operators, factorization of operators, multiplication operators, product spaces.

\section{REFERENCES}

[1] R. F. ARens And J. Eels JR., On embedding uniform and topological spaces, Pacific J. Math 6 (1956), 397-403.

[2] J. M. Calabuig, O. Delgado and E. A. Sánchez Pérez, Generalized perfect spaces, Indag. Math. 19 (2008), 359-378.

[3] J. A. CháveZ-Domínguez, Lipschitz $p$-convex and q-concave maps, arXiv:1406.6357 [math.FA].

[4] A. Defant, Variants of the Maurey-Rosenthal theorem for quasi Köthe function spaces, Positivity 5 (2001), 153-175.

[5] A. Defant And E. A. SÁnchez PÉREZ, Maurey-Rosenthal factorization of positive operators and convexity, J. Math. Anal. Appl. 297 (2004), 771-790.

[6] A. Defant And E. A. SÁnchez PÉRez, Domination of operators on function spaces, Math. Proc. Camb. Phil. Soc. 146 (2009), 57-66.

[7] O. Delgado And E. A. SÁnchez PÉREZ, Summability properties for multiplication operators on Banach function spaces, Integr. Equ. Oper. Theory 66 (2010), 197-214.

[8] O. Delgado And E. A. SÁnchez PÉREZ, Strong factorizations between couples of operators on Banach function spaces, J. Convex Anal. 20, 3 (2013), 599-616.

[9] M. Dubei, E. D. Tymchatyn And A. Zagorodnyuk, Free Banach spaces and extension of Lipschitz maps, Topology 48, 2-4 (2009), 203-212.

[10] J. Lindenstrauss And L. TZafriri, Classical Banach Spaces II, Springer, Berlin, 1979.

[11] G. YA. Lozanovs KiI, On some Banach lattices, Siberian Math. J. 10 (1969), 419-430.

[12] L. Maligranda And L. E. Persson, Generalized duality of some Banach function spaces, Indag. Math. 51 (1989), 323-338.

[13] S. OKada, W. J. Ricker And E. A. SÁnChez PÉrez, Optimal Domain and Integral Extension of Operators acting in Function Spaces, Oper. Theory Adv. Appl., vol. 180, Birkhäuser, Basel, 2008.

[14] N. Weaver, Lipschitz Algebras, World Scientific Publishing Co., Singapore, 1999.

[15] P. WojtaszCZY K, Banach Spaces for Analysts, Cambridge University Press, Cambridge, 1991.

[16] A. C. ZAANEN, Integration, 2nd rev. ed., North Holland, Amsterdam, 1967. 